\title{
Transcutaneous Electrical Acupoint Stimulation Before Induction of Anesthesia Prevents Sufentanil- Induced Cough: A Prospective, Randomized, Controlled Study
}

\section{Junjie Xie}

Wenzhou Medical University First Affiliated Hospital

Yunchang Mo

Wenzhou Medical University First Affiliated Hospital

Junkai Wang

Zhejiang Provincial People's Hospital

\section{Lili Yang}

Lishui Central Hospital and Fifth Affiliated Hospital of Wenzhou Medical College

Haijuan He

Taizhou Hospital of Zhejiang Province

Junlu Wang ( $\square$ wangjunlu973@163.com )

First affiliated hospital of Wenzhou medical university

\section{Research}

Keywords: Sufentanil, cough, TEAS, general anesthesia

Posted Date: October 27th, 2020

DOI: https://doi.org/10.21203/rs.3.rs-35069/v1

License: (c) (1) This work is licensed under a Creative Commons Attribution 4.0 International License.

Read Full License 


\section{Abstract}

Background. Sufentanil-induced cough is a common side effect during the induction of general anesthesia.This study is to determine the inhibitory effect of transcutaneous electrical acupoint stimulation(TEAS) on sufentanil-induced cough.

Methods. A total of 339 patients were recruited in this trial.After the unqualified patients were removed,300 patients were enrolled and randomly allocated into five groups( $n=60)$ :Patients did not receive TEAS in control group(C group);Patients received $2 \mathrm{~Hz}$ TEAS at Hegu/Neiguan(LI4/PC6) in 2A group;Patients received $100 \mathrm{~Hz}$ TEAS at LI4/PC6 in 100A group;Patients received $2 \mathrm{~Hz}$ TEAS at Zusanli/sanyinjiao(ST36/SP6) in 2B group;Patients received 100Hz TEAS at ST36/SP6 in 100B group.Except for $C$ group,all groups received TEAS for 30 min before the induction. Then $0.5 \mu \mathrm{g} / \mathrm{kg}$ sufentanil was given within $2 \mathrm{~s}$,the occurrence of cough was observed and recorded for $1 \mathrm{~min}$. The severity of cough was graded as mild(1-2 coughs),moderate( $3-5$ cough), and severe( $>5$ coughs).The mean arterial pressure(MAP) and heart rate(HR) before (T0) and $1 \mathrm{~min}$ after(T1) sufentanil injection were recorded.

Results. The incidence of sufentani-induced cough in C group,2A group,2Bgroup,100A group and 100B group were $37 \%, 27 \%, 27 \%, 12 \%$ and $13 \%$,respectively.Compared with $\mathrm{C}$ group,the incidence of $100 \mathrm{~A}$ group and 100B group were significantly lower $(\mathrm{P}<0.05)$. The MAP and HR between five groups had no statistical difference.

Conclusion. Groups the received $100 \mathrm{~Hz}$ TEAS for 30 min before sufentanil injection can effectively reduce the incidence of sufentanil-induced cough during the induction of general anesthesia.

Trial registration: Chinese clinical trial registry(ChiCTRINR16008759)

\section{Introduction}

Sufentanyl,an opioid analgesic drug,is widely used in clinical anesthesia due to its strong analgesic effect,rapid-onset,and stable cardiovascular effects. However,intravenous sufentanil injection can evoke cough,which increases risk during anesthesia.A previous report(1) showed that the incidence of sufentanil-induced cough is about $28 \%$ in Asian individuals.Although sufentanil-induced cough is transient and benign for the most time,it could cause serious consequences in cases with ocular trauma,pneumothorax,a reactive/difficult airway,artery dissection,or patients undergoing neurosurgery(2).Given the highly contgious nature of some pandemic,such as COVID-19,if the patient cough during the induction,tracheal intubation carries a high risk of transmission to the intubator.

Many studies have sought an effective approach to suppress the sufentanil-induced cough during anesthesia induction.These approaches including pre-induction with i.v. lidocaine,ephedrine(3),dexamethasone(4),ketamine(5),clonidine(6),dexmedetomidine(1), and $\beta$-receptor blocker inhalation(7).However,these methods each have limitation and are not widey used. 
TEAS has an analgesic effect,reduces the perioperative inflammatory response,and promotes immune function and oxygenation. TEAS has been proved to have a significant effect on the treatment of lung diseases, such as COPD, asthma, etc $(8,9)$. But for the time being,no researchers have used TEAS to prevent sufentanil-induced cough. Therefore,we postulated that patients receive TEAS for 30 min before administration of sufentanil may suppress the undesirable cough.We here tested this hypothesis in a prospective,multicenter,double-blind,randomized, controlled clinical trial.

\section{Materials And Methods}

This study was conducted after approval from the ethics committee of the First Affiliated Hospital of Wenzhou Medical University(2016 - 142)(Wenzhou,China) and registered at the Chinese Clinical Trial Registry(ChiCTR-INR-16008759).Written informed consent was obtained from all patients.

We considered patients of either sex for inclusion if they were aged between 20 and 75 years,had an ASA physical status $₫$ or $\Downarrow$,and were undergoing elective surgical procedures under general anesthesia.

The exclusion criteria were as follows:any incision or surgical scar in an acupoint;infection in an acupoint;nerve injury in the upper or lower limbs;a history of spinal surgery;allergic reaction to drugs used in the test;sinus bradycardia;severe neurological disease(intracranial hypertension,cerebral hernia,cerebral tumor,cerebral aneurysm); severe respiratory disease(asthma,pneumothorax,chronic obstructive pulmonary disease,bronchial hyperresponsiveness);smoking;severe cardiovascular disease(myocardial infarction,aortic dissection); addiction to anaesthetic or recent history of opioid use;upper respiratory tract infection in the previous 2 weeks;biliary tract surgery;or treatment with angiotensin-converting-enzyme inhibitors(ACE-inhibitors).

This study was conducted from August 2016 to July 2019 at First Affiliated Hospital of Wenzhou Medical University.300 patients were randomly and equally divided into five groups $(n=60)$ :Patients did not receive TEAS in control group(C group);Patients received $2 \mathrm{~Hz}$ TEAS at the bilateral LI4/PC6 in 2A group;Patients received $100 \mathrm{~Hz}$ TEAS at the bilateral LI4/PC6 in 100A group;Patients received $2 \mathrm{~Hz}$ TEAS at the bilateral ST36/SP6 in 2B group;Patients received $100 \mathrm{~Hz}$ TEAS at the bilateral ST36/SP6 in 100B group.The locations of all the acupoints have been showed in Fig. 1.

Except for $\mathrm{C}$ group,other groups were received TEAS for $30 \mathrm{~min}$ before induction of anesthesia.Venous access was established using a $22 \mathrm{G}$ cannula on the dorsum of the non-dominant hand,before entering the operating room.No medication other than crystal liquid was given.Upon arrival in the operating room,non-invasive blood pressure,oxygen saturation, and electrocardiography were recorded.After commencing induction of anesthesia,sufentanil $(0.5 \mu / \mathrm{kg})$ was given within $2 \mathrm{~s}$. An independent observer observed and recorded the occurrence of cough after sufentanil administration in 1 min. The severity of cough was graded as mild(1-2 coughs), moderate( $3-5$ coughs), and severe( $>5$ coughs).After this observation finished,propofol $(2 \mathrm{mg} / \mathrm{kg}$ ) and rocuronium $(1 \mathrm{mg} / \mathrm{kg})$ were given and endotracheal intubation was achieved.MAP and HR before(T0) and 1 min after(T1) sufentanil injection were recorded. 
In the time from sufentanil administration to successful endotracheal intubation,an oxygen mask was given if the blood saturation was $<90 \%$;norepinephrine was given if the systolic blood pressure(SBP) was $<90 \mathrm{mmHg}$ or the diastolic blood pressure(DBP) was $<60 \mathrm{mmHg}$; and atropine $0.5 \mathrm{mg}$ was given if the HR was $<50 /$ min.

\section{Statistical analysis}

The required sample size was estimated based on a $30 \%$ reported incidence of sufentanil-induced cough, and an assumption that TEAS would reduce the incidence of cough to $8 \%$, according to a pilot study. With $a=0.05$ and $\beta=0.20$, a minimum of 60 patients per group were required.

We use a randomization table to randomize patients. The random numbers were divided by 5 ; the remainder of the division sum $(0,1,2,3,4)$ was used to decide the allocation to each of the 5 groups.

All test data are expressed as mean \pm standard deviation, and SPSS 20.0 software was used for statistical analyses. Demographic characteristics were compared using independent samples u-test. The cough incidence was compared using the chi-square test, and cough severity was compared using the Mann-Whitney $U$ test or Kruskal-Wallis test. $P<0.05$ was considered statistically significant.

\section{Result}

A total of 339 patients were recruited from August 2016 to July 2019, 39 unqualified patients were removed,300 patients were enrolled finally ( 5 patients with history of asthma,19 patients were smoking, 15 patients were taking ACE inhibitor)(Fig. 2).

The patient characteristics(age,weight,sex) in the 5 groups have no difference(Table 1). The incidence of sufentani-induced cough in $\mathrm{C}$ group,2A group,2Bgroup,100A group and 100B group were $37 \%, 27 \%, 27 \%, 12 \%$ and $13 \%$,respectively.Compared with $\mathrm{C}$ group,the incidence of $100 \mathrm{~A}$ group and $100 \mathrm{~B}$ group were significantly lower $(\mathrm{P}<0.05)($ Table 2$)$. The severity of cough did not show statistical difference(Table 3). The MAP and HR between five groups had no statistical difference(Table 4,Table 5).After the injection of sufentani,no patients showed a low blood oxygen saturation $\left(\mathrm{SpO}_{2}<90 \%\right.$ ), low blood pressure, apnea, nausea, vomiting, or any other adverse reactions. 
Table 1

Characteristics of patients in Part 2. Values are the mean (SD).

\begin{tabular}{|llllll|}
\hline & Age, years & Sex, M/F & Weight, kg & Height, cm & ASA 1/2 \\
\hline C Group & $47(13)$ & $17 / 43$ & $62(11)$ & $161(7)$ & $23 / 37$ \\
\hline 2A Group & $47(14)$ & $13 / 47$ & $61(11)$ & $162(7)$ & $26 / 34$ \\
\hline 2B Group & $48(13)$ & $16 / 44$ & $62(11)$ & $163(7)$ & $21 / 39$ \\
\hline 100A Group & $47(12)$ & $19 / 41$ & $61(12)$ & $161(8)$ & $20 / 40$ \\
\hline 100B Group & $48(12)$ & $15 / 45$ & $61(10)$ & $161(7)$ & $19 / 41$ \\
\hline \multicolumn{4}{|l}{ The Characteristics of patients did not differ significantly in the 5 groups $(P>0.05)}$. \\
\hline
\end{tabular}

Table 2

Incidence of cough in patients in Part 2. Values are the number (proportion).

\begin{tabular}{|lrrrrr|}
\hline & C Group & 2A Group & 2B Group & 100A Group & 100B Group \\
\hline Incidence of cough & $22(37 \%)$ & $16(27 \%)$ & $16(27 \%)$ & $7(12 \%)^{*}$ & $8(13 \%)^{*}$ \\
\hline${ }^{*} \mathrm{p}<0.05$ compared with C Group. & & & \\
\hline
\end{tabular}

Table 3

Severity of cough in patients in Part 2. Values are the number.

\begin{tabular}{|llllll|}
\hline Severity of cough & C Group & 2A Group & 2B Group & 100A Group & 100B Group \\
\hline Mild & 12 & 8 & 7 & 4 & 4 \\
\hline Moderate & 7 & 7 & 7 & 2 & 2 \\
\hline Severe & 3 & 1 & 2 & 1 & 2 \\
\hline
\end{tabular}


Table 4

The heart rate (HR) before (T0) and after (T1) sufentanil administration. Values are the mean (SD).

\begin{tabular}{|lll|}
\hline & \multicolumn{1}{l|}{ HR (bpm) } \\
\cline { 2 - 3 } & T0 & T1 \\
\hline C Group & $80(12)$ & $79(11)$ \\
\hline 2A Group & $79(14)$ & $79(14)$ \\
\hline 2B Group & $77(11)$ & $76(11)$ \\
\hline 100A Group & $77(13)$ & $77(13)$ \\
\hline 100B Group & $81(12)$ & $81(11)$ \\
\hline $\begin{array}{l}\text { The HR before and after sufentanil administration did not differ significantly in the } 5 \text { groups }(P> \\
\text { 0.05). }\end{array}$ \\
\hline
\end{tabular}

Table 5

The mean arterial pressure (MAP) before (T0) and after (T1) sufentanil administration. Values are the mean (SD).

\begin{tabular}{|lll|}
\hline & \multicolumn{2}{l|}{ MAP (mmHg) } \\
\cline { 2 - 3 } & T0 & T1 \\
\hline C Group & $97(14)$ & $96(13)$ \\
\hline 2A Group & $100(16)$ & $99(16)$ \\
\hline 2B Group & $94(11)$ & $94(12)$ \\
\hline 100A Group & $101(13)$ & $98(13)$ \\
\hline 100B Group & $95(12)$ & $96(12)$ \\
\hline $\begin{array}{l}\text { The MAP before and after sufentanil administration did not differ significantly in the } 5 \text { groups }(\mathrm{P}> \\
\text { 0.05). }\end{array}$ \\
\hline
\end{tabular}

\section{Discussion}

Our study revealed that using TEAS at a frequency of $100 \mathrm{~Hz}$ for $30 \mathrm{~min}$ at the bilateral LI4/PC6 and ST36/SP6 acupoints before induction of general anesthesia can significantly reduce the incidence of sufentanil-induced cough.

Sufentanil is a new type of synthetic opioid drug that is widely applied for the rapid induction of anesthesia. However, i.v. injection of fentanyl can evoke coughing, which increases the risks associated with anesthesia. Li et al(10) has suggested that use of peripheral i.v. sufentanil $0.5 \mu \mathrm{g} / \mathrm{kg}$ during anesthesia induction was associated with a cough incidence of $37 \%$.An et al(11) found that the incidence of sufentanil-induced cough could be $45.8 \%$ by using $1 \mu \mathrm{g} / \mathrm{kg}$ sufentanil. 
Although the mechanism is unclear, it may involve the following $(12,13)$. $\otimes$ Opioid receptors are divided into $\mu, K, \delta, \sigma$ types, depending on their activation. It is possible that a particular type of opioid receptor present in the airway plays an important role in mediating the sufentanil-induced cough. $\nabla$ Acute conditioning of rapidly adapting stretch receptors (RARS) and C-fibers may play a role. In particular, the laryngeal and tracheal RARS in the bronchial tree, probably act as the primary sensory pathways of the cough reflex. C-fibers can not only induce cough by releasing tachykinin, which activates RARS, but can also cause neurogenic inflammation, and inhibit the cough reflex through a central gating mechanism. Intravenous sufentanil may cause bronchial smooth muscle contraction, and activation of RARS in the adjacent regions may cause coughing. $\triangle$ Airway high reactivity (AHR) is considered to play a role in sufentanil-induced coughing.

Many previous studies have aimed to suppress sufentanil-induced cough by injecting exogenous drugs, such as lidocaine, ephedrine(3), dexamethasone(4), ketamine(5), clonidine(6), and dexmedetomidine(1),but they also bring side effects like hemodynamic instability, arrhythmia, etc.

Electroacupuncture is widely used in the clinic as an analgesic(14) and as a means to achieve perioperative multiple organ function protection $(15,16)$. Previous studies have suggested that the endogenous opioid peptides enkephalin, beta-endorphin, and dynorphin are involved in mediating the analgesic effect of electroacupuncture(17). Another previous study demonstrated that low and high frequency TEAS, given for 30 min, could increase the enkephalin and dynorphin levels in human lumbar $\operatorname{CSF}(18)$.

In our study,we found that patients received $100 \mathrm{~Hz}$ can effectively prevent sufentanil-induced cough,either LI4/PC6 or ST36/SP6.We hypothesized that the mechanism of this phenomenon is the increase dynorphin in CSF after TEAS. The production of endogenous opioid peptides is the basis of electroacupuncture analgesia. Abundant opioid receptors are located in the central nervous system (CNS), such as the head of the caudate nucleus, the nucleus accumbens, the amygdaloid nucleus, the periaqueductal gray, and the nucleus raphe magnus(19). With the change of electroacupuncture frequency,the opioid peptides produced will also change.Low frequency electroacupuncture produces enkephalin,while high frequency electroacupuncture produces dynorphin,either LI4/PC6 or ST36/SP6(18, 20-21).Opioids may inhibit cough reflex by acting directly on the cough center in the medulla, a highly selective к-opioid receptor agonist has potent antitussive effects when administered either i.c.v. or i.p., and that $\mu 2$ - rather than $\mu 1$-opioid receptors are involved in the $\mu$-opioid receptor-induced antitussive affects $(22,23)$.Therefore,We consider that the possible mechanism underlying this phenomenon is the $100 \mathrm{~Hz}$ TEAS-mediated release of dynorphin into the CSF, leading in part to $\mathrm{k}$-receptor activation, which could then have an antitussive effect,while the endorphins produced by $2 \mathrm{~Hz}$ TEAS could not selectively activate the $\mu 2$-receptor.

In addition, a previous study(24) found that sedation could inhibit sufentanil-induced cough; the sedative effect of TEAS may be one of the reasons for inhibition of sufentanil-induced cough by TEAS. 
In recent years, there are more and more applications of electroacupuncture in the perioperative period. This study found a new role of electroacupuncture in the perioperative period, providing clinical evidence for the study of the mechanism of electroacupuncture.

The study had some limitations. Firstly, we could not use an antagonist in patients. Secondly, we only chose the number of coughs as the primary outcome, and did not investigate any other biochemical factors in our study. Thirdly, the size of the electrode slice we used was about $3.5 \mathrm{~cm} \times 3.5 \mathrm{~cm}$, which was too large to avoid affecting other acupoints; therefore, we did not set up a non-acupoint group. These limitations should be addressed in future research.

\section{Declarations}

\section{Ethics approval and consent to participate}

This study was conducted after approval from the ethics committee of the First Affiliated Hospital of Wenzhou Medical University(2016-142)(Wenzhou,China) and registered at the Chinese Clinical Trial Registry(ChiCTR-INR-16008759),July $1^{\text {st }} 2016$, http://www.chictr.org.cn/index.aspx.Written informed consent was obtained from all patients.

\section{Consent for publication}

Not applicable.

\section{Availability of data and materials}

Following the publication of the main trial results anonymous data sets will be available with agreement from Professor Junlu Wang,First affiliated hospital of Wenzhou university,China.

\section{Competing interests}

The authors declare that they have no competing interests.

\section{Funding}

This study was supported by Wenzhou Municipal Science and Technology Bureau (award number:2018Y1122). The funding body had no role in the design of the study and collection,analysis and interpretation of data and in writing the manuscript.

\section{Authors' contributions}

JJX,YCM and JLW conceived and designed the experiments of the current study.HJH and LLY performed the experiments.JJX wrote the manuscript.JKW analyzed the data.All authors approved the final version of the manuscript. 


\section{Acknowledgment}

Not applicable.

\section{References}

1. Shen Sun,Shao-qiang Huang.Effects of pretreatment with a small dose of dexmedetomidine on sufentanil-induced cough during anesthetic induction.J Anesth(2013)27:25-28

2. Yu M-S,Kim JY,Kim HY.Intravenous dexamethasone pretreatment reduces remifentanil induced cough.Korean J Anesthesiol.2011;60(6):403-7

3. Lin CS, Sun WZ, Chan WH, Lin CJ, Yeh HM, Mok MS. Intravenous lidocaine and ephedrine, but not propofol, suppress fentanyl-induced cough. Can J Anaesth. 2004;51(7):654-659.

4. Lin JA, Chen FC, Lee MS, Horng HC, Cherng $\mathrm{CH}$, Yeh CC, Wong CS. Intravenous dexamethasone pretreatment reduces fentanyl-induced cough. J Formos Med Assoc. 2007 Aug;106(8):649-55.

5. Yeh CC, Wu CT, Huh BK, Lee MS, Lin SL, J Sheen M, Wong CS. Premedication with intravenous lowdose ketamine suppresses fentanyl-induced cough. J Clin Anesth. 2007 Feb;19(1):53-6.

6. Horng HC, Wong CS, Hsiao KN, Huh BK, Kuo CP, Cherng CH, Wu CT. Pre-medication with intravenous clonidine suppresses fentanyl-induced cough. Acta Anaesthesiol Scand. 2007 Aug;51(7):862-5.

7. Lui PW,Hsing $\mathrm{CH}$,Chu YC.Terbutaline inhalation suppresses fentanyl-induced coughing.Can J Anaesth.1996;43(12):1216-9.

8. Wang J, Li J, Yu X, Xie Y. Acupuncture Therapy for Functional Effects and Quality of Life in COPD Patients: A Systematic Review and Meta-Analysis. Biomed Res Int. 2018;2018:3026726.

9. Li M, Zhang X, Bao H, Li C, Zhang P. Acupuncture for asthma: Protocol for a systematic review. Medicine (Baltimore). 2017;96(26):e7296.

10. Li J, Li K. Effects of pre-inhalation of salbutamol on cough reflex induced by Sufentanil. In: Sadeghian SH, Mehta U, Rajbongshi P, ^editors. AER-Advances in Engineering Research; 2016. p. 237-9.

11. An LJ, Gui B, Su Z, Zhang Y, Liu HL. Magnesium sulfate inhibits sufentanil-induced cough during anesthetic induction. Int J Clin Exp Med. 2015;8(8):13864-13868.

12. Zhang Rui-dong,Chen Xi-ming,Chen Yu.The mechanism,influential factors and prevention of cough reflex induced by fentanyl [J].International Journal of Anesthesiology and Resuscitation,2006,27(6):369-371

13. Karlsson JA,Lanner AS,Persson CG.Airway opioid receptors mediate inhibition of cough and reflex bronchoconstriction in guinea pigs[J].J Pharmacol Exp Ther,1990,252(2):863-868.

14. Wang H, Xie Y, Zhang Q, Xu N, Zhong H, Dong H, Liu L, Jiang T, Wang Q, Xiong L. Transcutaneous electric acupoint stimulation reduces intra-operative remifentanil consumption and alleviates postoperative side-effects in patients undergoing sinusotomy: a prospective, randomized, placebocontrolled trial. Br J Anaesth. 2014 Jun;112(6):1075-82. 
15. Hsing WT,Imamura M,Weaver K, Fregni F, Azevedo Neto RS. Clinical effects of scalp electrical acupuncture in stroke: a sham-controlled randomized clinical trial. J Altern Complement Med. 2012 Apr;18(4):341-6.

16. Kim KH, Lee MS, Kim TH, Kang JW, Choi TY, Lee JD. Acupuncture and related interventions for symptoms of chronic kidney disease. Cochrane Database Syst Rev. 2016 Jun 28;(6):CD009440.

17. Wen YR,Yeh GC,Shyu BC,Ling QD,Wang KC.A minimal stress model for the assessment of electroacupuncture analgesia in rats under halothane.Eur J Pain 2007;11:733-742.

18. Han JS, Chen XH, Sun SL, Xu XJ, Yuan Y, Yan SC, Hao JX, Terenius L. Effect of low- and highfrequency TENS on Met-enkephalin-Arg-Phe and dynorphin A immunoreactivity in human lumbar CSF. Pain. 1991 Dec;47(3):295-8.

19. Sun SL,Han JS. High and low frequency eletroacupuncture analgesia are mediated by different types of opioid receptors at spinal level:a cross tolerance study.Acta Physiol Sin(Chin)1989;41:416-420.

20. Lee JH,Choi $\mathrm{YH}$,Choi BT.The anti-inflammatory effects of $2 \mathrm{HZ}$ electroacupuncture with different intensities on acute carrageenan-induced inflammation in the rat paw.Int J Mol Med 2005;16:99-102.

21. Han JS.Acupuncture:neuropeptide release produced by electrical stimulation of different frequencies.Trends Neurosci.2003;26:17-22.

22. Phua WT, Teh BT, Jong W, Lee TL, Tweed WA. Tussive effect of a fentanyl bolus. Can J Anaesth. 1991;38(3):330-334.

23. Kamei J. Role of opioidergic and serotonergic mechanisms in cough and antitussives.Pulm Pharmacol. 1996 Oct-Dec;9(5-6):349-56.

24. Wang L, Yao JH, Zhu JJ, Liu B, Zhu JG, Zhou DC. Effect of optimizing anesthetic injecting sequence during induction on fentanyl-induced coughing. Zhonghua Yi Xue Za Zhi. 2010 Apr 6;90(13):921-3.

\section{Figures}




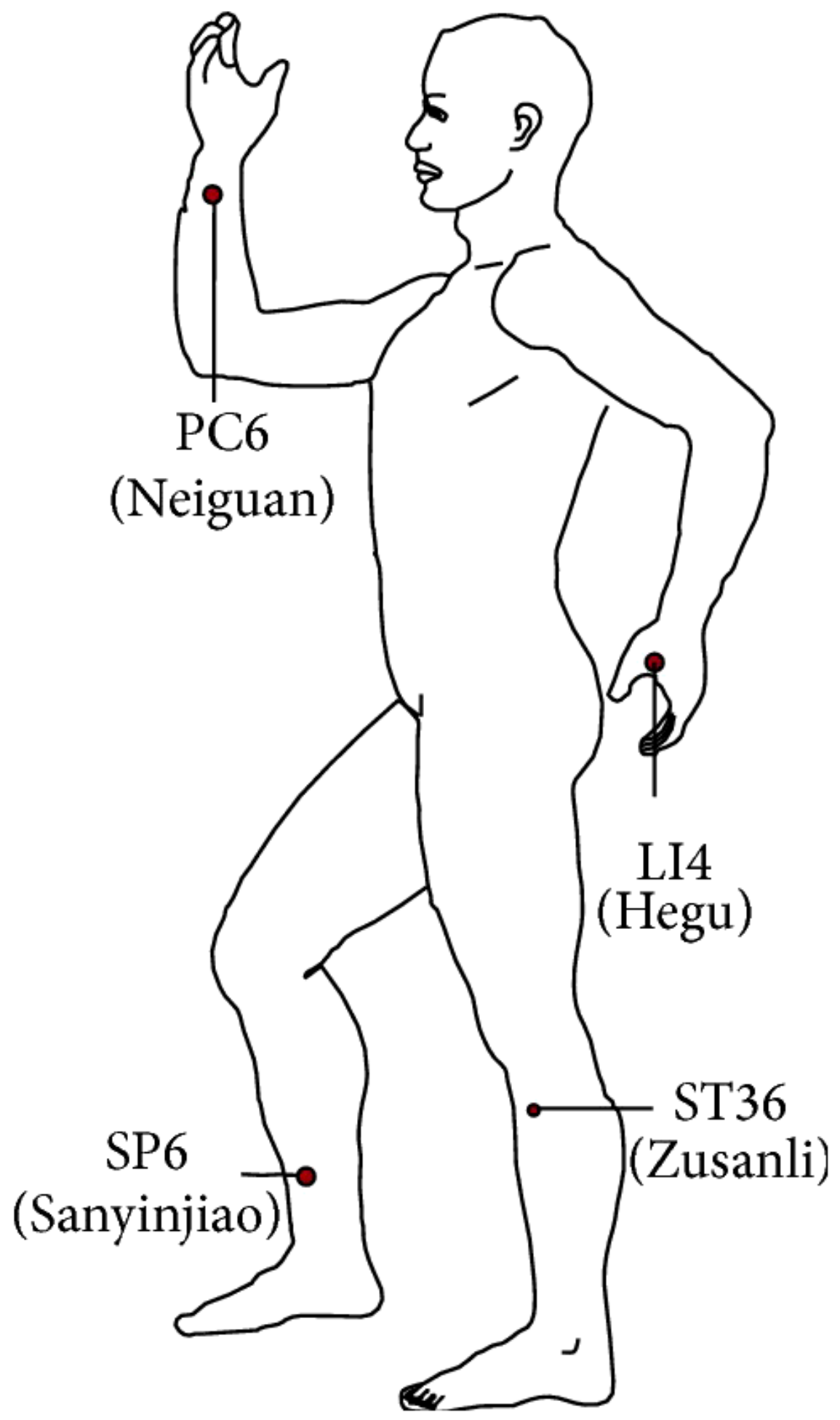

Figure 1

Location of LI4/PC6 and ST36/SP36 


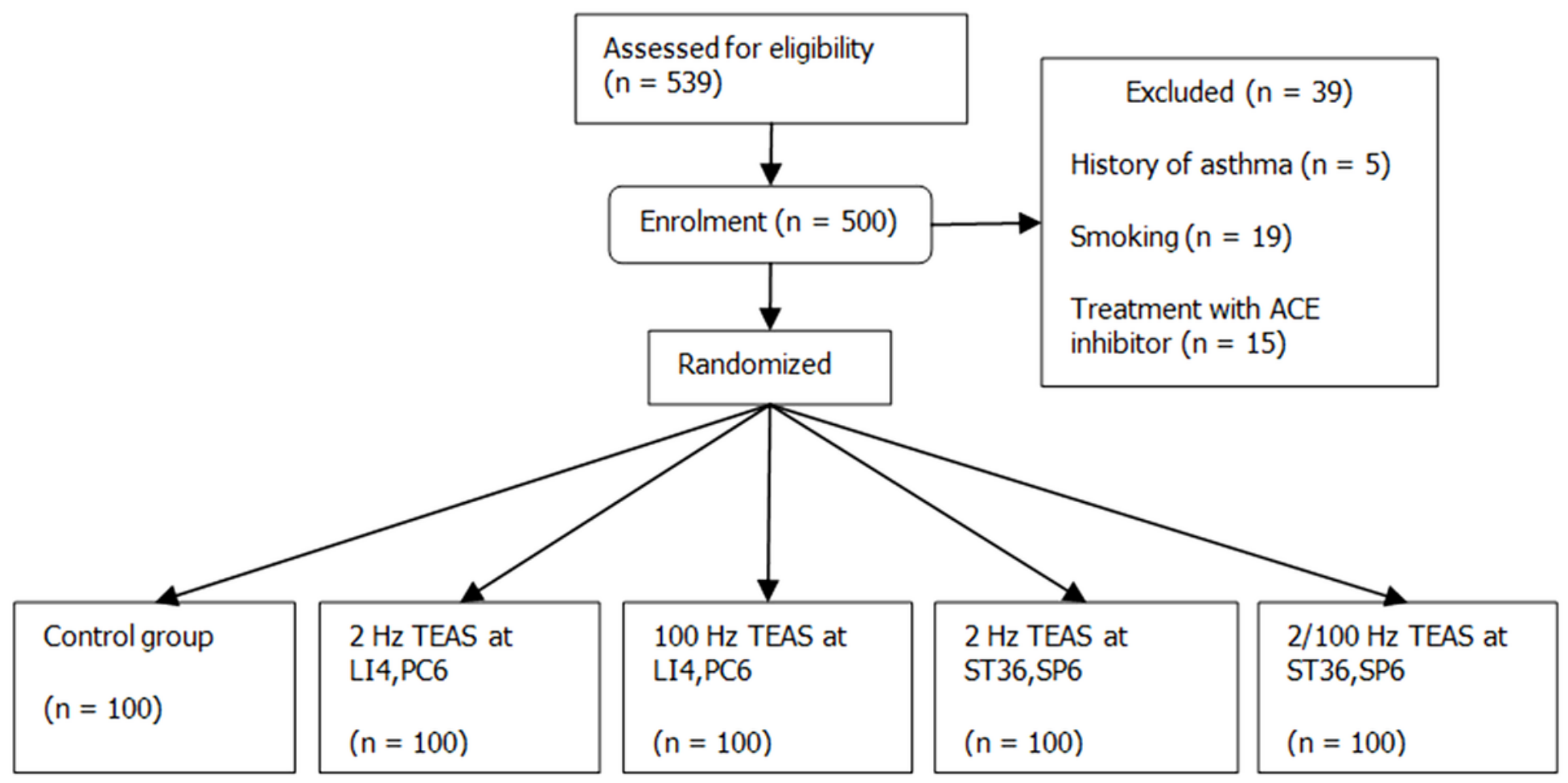

Figure 2

Number of patients included and excluded from the Part 2.

\section{Supplementary Files}

This is a list of supplementary files associated with this preprint. Click to download.

- CONSORT2010Checklist.doc 